\title{
DISCUSSION ON PAPER 8550
}

\section{Exploration, evaluation and development of large-scale groundwater supplies in the Botswana Kalahari}

\author{
S. S. D. Foster, C. D. Mackie and P. Townend
}

\section{Mr Foster, Mr Mackie and Mr Townend}

During 1982, the cumulative wellfield abstraction from the Jwaneng groundwater supply increased from a little over $1000 \mathrm{Ml}$ to beyond $5000 \mathrm{Ml}$. Regional drawdowns continued significantly less than predicted in the worst case, and the state of resources looked most satisfactory. Some isolated operational problems have been encountered in individual boreholes, relating to pump performance, corrosion and excess drawdown. These are being handled on an ad hoc basis.

\section{Dr M. H. de Freitas, Imperial College}

Although the geophysical data appear to have been treated in an analytical way ( $\$ 14)$, was the end product assessed qualitatively or quantitatively?

46. On reflection, to what extent does a knowledge of the basic geological history of the area reveal the nature and extent of the principal hydrogeological problems?

47. What were the principal hydrogeological boundaries?

\section{Mr K. J. Edworthy, Binnie \& Partners}

The Authors seem to have been able to do quite a large suite of different types of investigation work in getting towards their answers. Usually a pre-development groundwater investigation is cut back to the bone, and beyond, and it is interesting to see the proportion of the investigation costs compared with the total capital cost. In the figure of $\$ 1.85$ million quoted for the total cost of the investigation, are the costs of the tritium work and the other research-type investigations included? If not, what effect do they have on the overall cost?

49. Do the Authors think that the proportion of investigation cost to capital cơst is a fair one for the average developing-country groundwater development of this type and size? Also, with the benefit of hindsight, which techniques would they regard as being superfluous? Looking back, at what point would they say that the expenditure would have been at an optimum?

Mr G. P. Jones, University College, London

As someone who was involved in this work in both the field work and the office work, including the mathematical modelling (in the feasibility stage), I find my

Paper published: Proc. Instn Civ. Engrs, Part 1, 1982, 72, Nov., 563-584. 
recollection slightly at odds with what the Authors have reported. My recollection is that we did not start off with the idea of a virgin territory. Previous work provided a rough framework (certainly no details) of the stratigraphy. We were looking for basins and therefore for basin margins; to that extent we had a conceptual model or idea in mind. I know in my own case that once we discovered the central basement ridge that separated the deeper western basin from the more shallow eastern basin, it became a matter of trying in sedimentological terms to envisage conditions that could give rise to coarser deposits adjacent to the basin ridges. Moreover, in the specific area that I eventually defined for the model, there were at least half a dozen logged holes done for coal. If one inverted the main $\log$ (a neutron log) that had been run by a specialist firm for these holes, one in effect got a gamma-ray log which could be related to the gamma-ray logging undertaken as drilling proceeded. (I am not talking about the production holes, but about the early stages when the 'investigation' holes were being put down.) It was not a question of waiting until the hole was finished, for the driller had to be told where the slotted linings were to be placed, which meant that the hydrogeologists could be called out at any hour of the day or night to do the logging. It also meant that this information was being gathered all the time and assessed in the field (not sent back to any office), and that decisions were made on the spot as to where to move for the next hole in the light of the information gathered from the previous holes. There was no fixed programme as regards the number of holes. I do not know to what extent the model has been subsequently refined. In the absence of historical data, there was no way of verifying the model; it was a question of testing the sensitivity of the parameters being used in all possible combinations of conditions. Once we had the conception of a couple of basins partially separated by the ridge, with a very well marked fault feature delineating the northern end of the basin, there was then a relatively simple approach to the model and the modelling was very simple. Such an approach was conventional at the time; basically it was very simple modelling of unverified data. A worst possible condition was envisaged and we did not even anticipate a situation where the drawdowns would be such as to change the storativity to unconfined values.

51. What worries me is that from the title of the Paper people will think that this is how groundwater studies are made rather than how they should be made in different parts of the world. The only other project I have been involved in with a similar approach was again one where there was a significant component of private money. That was in the pre-revolution days in Libya when Occidental Oil was developing a scheme at Kufra. That scheme was connected with oil; this one is connected with diamonds. When one is looking. for a conventional water supply one will never have this kind of money to spend and therefore the whole approach will have to be different in terms of scale. Most of the conventional water supply schemes do not have such an intensity of boreholes and information.

\section{Mr R. W. Simpson, Howard Humphreys \& Partners}

This is the first time I have seen a paper on a groundwater project that has set out the planning and costing aspects of water exploration in addition to the conventional scientific aspects of hydrogeology. But one must be cautious in taking the investigations as typical of what hydrogeologists are doing world-wide, especially in the arid zones. In public water supply schemes in arid zones one is only able to invest something like $1 \%$ of the capital cost in the investigation, whereas this 
particular project would appear to have a $15 \%$ investigation budget. I have been finishing a public water supply project in the Middle East and $1 \%$ was a very high expenditure for such a scheme.

53. In the case described in the Paper there was also the advantage of being able to phase the programme with investigation, whereas with public water supply schemes there is usually a rush to bring water supplies through much quicker.

54. It is even more surprising that the investigation cost was so high when one considers that mineral exploration holes might have provided data. Quite often in mining projects there is supplementary information from the mining house itself.

55. There are rather conservative assumptions made in terms of resources: no recharge is assumed; the Authors have assumed mining. I am surprised at this conservatism.

\section{Mr R. J. White, National Water Council}

I was responsible, on behalf of Sir Alexander Gibb and Partners (funded by the UNDP), for the investigations of groundwater in the Cave sandstone around the Orapa mining complex mentioned in $\S 1$. This is some 200 miles to the north of the Jwaneng project described by the Authors but is still in the Kalahari. The Authors rightly describe the Orapa groundwater as a standby supply, but at the time of the investigation in 1969 it was essential for development of the mine while works to bring in surface water supplies were under construction. We were cautious in our appraisal and I would support the Authors in their conservative approach to the evaluation of groundwater. It is better to increase estimates later than to mislead investors by over-optimism initially.

57. We also considered it prudent in the Orapa investigations, as the Authors have at Jwaneng, not to assume any recharge of the aquifer, even though a small amount was likely. We regarded the aquifer as a confined system containing fossil water, and in both cases, at Jwaneng and Orapa, the development of the groundwater has been regarded as mining. The Authors raise a philosophical question in $\S 28$ about the mining of groundwater in a semi-arid region, but decline to discuss it. This philosophical question might seem odd to a mining engineer, whose whole business is concerned with exploiting non-renewable resources. It is important to warn of the consequences of overdrawing water resources, but if there is a case where mining of groundwater is likely to be justified it is surely in association with the mining of minerals.

58. The Paper does well to set out the evidence on which sound decisions can be made. It may be that in parts of the Kalahari a greater risk than overexploitation of the groundwater is overgrazing of the land when water is too readily available. Can the Authors be drawn on that proposition?

59. The conclusion from the analysis of pumping tests at Orapa was that the principal groundwater storage occurred under leaky artesian conditions in the indurated top $3 \mathrm{~m}$ of the Cave sandstone. ${ }^{3}$ At Jwaneng it was in the Ecca rather than the Cave sandstone, and over a much greater depth, that the sources of supply were found. Other pioneering investigations of Kalahari groundwater have been carried out by the Botswana Geological Survey, but the Authors' studies have been much more sophisticated than any done hitherto. The truly remarkable feature of all this work is the apparent extent of underground water resources beneath the semi-arid Kalahari. Could the Authors comment on the differences and similarities in the findings of the various investigations? 


\section{Mr P. R. Spray}

I was working in the Ministry of Mineral Resources and Water Affairs during part of the time of the project as a planner.

61. \$1.8 million sounds an awful lot, but the total cost of the diamond mining project was in the region of $\$ 350$ million, so in terms of the amount that was being asked of the mining company or, indeed, of the government, it did not sound enormous.

62. I think the conservative assumptions that were made were important to the people who were making the decisions. The alternative uses, although they were only small, were important to the Permanent Secretary, and therefore it was important to have conservative assumptions.

63. It seems to me that one difference between public water supplies and a new project like this is that in the case of public water supplies the demand is relatively clear, at least in the short term. In the case of a new project this may not be so. There was a power station project where the option was dry cooling as opposed to wet cooling: possible water demands within a very wide range were being submitted to the hydrogeologists, who were being told to get on with it.

64. The Authors make the point ( $\S 1)$ that the costs and effectiveness of diamond recovery methods vary widely with the water supply availability. It would be interesting to know to what extent the plant at a mine can be modified to take account of the shortages of water. This obviously has immediate relevance to the problem of mining water. In this case the advantages of the diamond mine coming off as soon as possible were very clear to everyone, and I think the decision was very straightforward, particularly once the conservative assumptions had been made, but I can see that there could have been more knife-edge problems. Could the Authors comment on the pricing of water coming from an unrecharged supply?

\section{The Chairman, Mr D. A. D. Reeve}

It is not at all unusual for water quality to vary from bore to bore and to vary with time. I wonder whether there was any indication that this was going to happen or had indeed already happened? Generally, I take it that the quality was very good.

\section{Mr Foster, Mr Mackie and Mr Townend}

In reply to $M r$ Edworthy, Mr Jones and Mr Simpson, we consider that the level of investment in groundwater investigation must be some proportion, albeit rather arbitrarily defined, of the maximum water development cost for the related project (be it in mining, industry or agriculture) to be viable, in terms of the method of economic analysis employed. In the case of potable water supply such a direct economic analysis is not realistic, but, in any case, numerous other overriding factors normally enter into consideration.

67. In the case in question, if the total investigation cost (US\$1.85 million) is compared to the actual (final) cost of ground water development (US\$11.4 million), the proportion spent on the former $(16 \%)$ appears very high. However, we suggest that it is more appropriate to consider only the costs of proving the groundwater supply feasible (US\$ 0.54 million) and justifying external pipeline construction (USS 0.82 million) and compare their total with the minimum cost of developing an alternative water-supply (US\$ 46 million), a very large sum for a supply of about $20 \mathrm{Ml} / \mathrm{d}$ but one which this particular enterprise could carry and remain 
viable. On this basis, and treating other groundwater investigation expenditure as part of the development costs, the proportion spent speculatively on groundwater investigation represents less than $3 \%$.

68. We are not clear as to the origin or logic of selecting a fixed proportion $(1 \%)$ of proposed water development costs for speculative investigation. Whatever the situation, however, it would seem highly illogical to suggest that the proportion used for groundwater schemes should be the same as for surface water schemes, since the latter almost always have higher development costs but, by their nature, much more limited investigation requirements. If the latter were the case, it would lead to unrealistic and counterproductive constraints on the terms of reference for the early stages of groundwater investigations.

69. We consider that the general approach adopted is logical for any commercial groundwater development, although clearly the investment in groundwater investigation, and thus the scale and intensity of such investigation, will vary widely with the economic returns on the water supply. As a contributor says, in the case of diamond mine or oilfield development this investment is likely to be at a maximum.

70. Since public water supply demands usually grow gradually, we would have thought that there would generally be both operational experience of groundwater supply on which to base further investigation and opportunity to phase new development. Groundwater is ideally suited to a phased expansion of development with growing population and/or water demand. However, where new, larger, better quality or more dependable supplies for a town are being sought in a new area distant from its existing sources, the situation will be comparable to that described in the Paper. Similar hydrogeological problems affecting engineering decision-making will probably occur. We can well believe that in such cases adequate funds for groundwater investigation may not be forthcoming. However, we would have thought that unavailability of such funds could prevent rational decisions on major investments, especially expenditure on external wellfield pipeline, which is always the major cost component in the development of a groundwater resource remote from the demand centre.

71. We are not clear whether the first question from $D r$ de Freitas refers specifically to surface geophysical surveys or geophysical borehole logging. The absence of strong geophysical contrasts between the aquifer units and the remainder of the Ecca sequence considerably restricts the application of surface geophysical surveys in an absolute sense, but both the surface gravimetric and magnetic survey data were treated analytically, by the method described. In the early stages of investigation, areas of different geophysical (primarily gravimetric) signature were selected for drilling to establish the corresponding geological environment (especially depth to basement) and any hydrological implications. Later the same data, coupled with magnetics to delineate the presence of any shallow intrusive rocks, were used tentatively to interpolate aquifer continuity, and thus, by implication, transmissivity. The geophysical logging was used as a quantitative tool to determine the preferred depth range for borehole screens or slotted linings, and for inter-borehole correlation of aquifer lithology and properties, defined from a small number of cored exploration boreholes.

72. We would prefer to phrase the second question from Dr de Freitas in a different way; namely, "to what extent did lack of a sound knowledge of the geological history of the area cause some of the principal hydrogeological problems defined?'. This was certainly the case. For example, a more detailed knowl- 
edge of the geological (sedimentological) history of the Ecca phase of the Karoo would have aided the exploration of aquifer occurrence and geometry, and given a clearer idea of aquifer boundaries, where not controlled by faulting. Furthermore, a reliable reconstruction of the more recent geological (palaeohydrological) history of the area would have helped to explain the origin of the fresh groundwater resources and given an insight on the continued existence of a small groundwater hydraulic gradient. During the course of the investigations a preliminary conceptual model of the geohydrological history of the aquifer was evolved, but long term field investigation and data compilation on a broader geographical scale are clearly required before a full understanding of the Kalahari aquifers is possible.

73. The figure of US $\$ 1.85$ million for the total investigation cost does include a realistic allowance (the figure of US\$ 0.31 million in Table 1) for the cost of the public-sector research work mentioned by $M r$ Edworthy.

74. The question of superfluous investigation techniques and optimum investigation expenditure is difficult to answer without some qualification, even with the benefit of hindsight. In the absence of political pressures and time constraints, we consider that some significant savings in the drilling programme could have been made by reducing drilling diameter, and thereby sacrificing aquifer pumping tests, at the feasibility stage. Of course, had the resource area been situated closer to the demand area, such that a low-cost temporary pipeline could have been laid to supply the construction and initial pilot stages of the mining project, groundwater development could have taken place progressively and the initial production pumping could have been monitored and used to provide confirmation of aquifer properties and boundaries. This would have resulted in major economies in the investigation budget.

75. While there were some indications from earlier work of possible target areas for major groundwater supply prospecting, there was nothing to indicate the feasibility of obtaining a supply of $20 \mathrm{Ml} / \mathrm{d}$, even in the short term. We think it would be more accurate to say that the conceptual model mentioned by Mr Jones was developed during the initial stages of the feasibility study, rather than prior to the start of that study.

76. The investigation programme, particularly the feasibility study, was very flexible. It benefitted greatly from such flexibility, which is not always a feature of groundwater investigation programmes. However, overall financial and technical control was maintained by regular site meetings, involving the representatives of both clients and various project advisers, at which the direction of the field work was reviewed. Moreover, the careful phasing of the investigation programme as a whole, with short intensive review periods between phases, was a key element in project planning.

77. We agree with Mr Jones's comments about the aquifer mathematical modelling. Although the model was, in fact, revised substantially in the later stages of the investigation programme, it can only be finally calibrated after some three years of closely monitored wellfield operational experience. Only at this stage will reliable estimates of the long term prospects for groundwater supply be confidently established.

78. Replying further to $M r$ Simpson, in this particular instance the geological exploration for the diamond mine was concentrated in an area of, coincidentally, poor groundwater prospects considerably to the south of the eventual groundwater development area, and thus very little useful hydrogeological information could be obtained from mine exploration. 
79. It is true that the hydrogeological assumptions used for the aquifer mathematical model were conservative. Mr Simpson cites only the issue of active groundwater replenishment or recharge. As is explained in the Paper, the evidence for a low rate of active recharge is very limited and rather questionable. In the context of proving an adequate water supply in the medium term, it therefore seemed more logical to ignore any active recharge and concentrate on the evaluation of exploitable groundwater storage. In the absence of well monitored operational experience, the quantification of this resource is complex and prone to rather large errors; thus sensible worst-case or conservative estimates were made to examine whether groundwater development remained viable. The aquifer mathematical model was also run with somewhat more optimistic hydrogeological parameters and this suggested that, with a relatively modest increase in the number of production boreholes, the required supply could be sustained for more than 20 years.

80. In reply to $M r$ White, the Botswana Geological Survey has recently published a geological map showing a revised distribution of Karoo strata in the Kalahari, based on aerial gravimetric and magnetic geophysical surveys and recent drilling data. This confirms the very widespread distribution of Karoo subcrop below the superficial cover of Kalahari Beds. The Ecca and Cave (Ntane) sandstones, the best prospects for large-scale groundwater supply, show a correspondingly wide distribution. However, it is not yet clear over what proportion of the Kalahari these sandstones possess sufficient transmissivity, contain sufficiently fresh water and occur at sufficiently shallow depth to be regarded as important aquifers.

81. The Cave (Ntane) Sandstone has a more extensive distribution than the more favourable sandstone facies of the Ecca and is once again the current subject of intensive investigation in the Orapa area. The interest is to expand the available groundwater supply to some $12 \mathrm{Ml} / \mathrm{d}$, to be used conjuctively in the long term with supplies from a surface reservoir. The formation has the significant advantage of being much more uniform in lithological and hydraulic properties areally, with fairly consistent, useful permeability developments in both an upper (basalt contact) zone and a basal zone. However, the total formation transmissivity (generally less than $20 \mathrm{~m}^{2} / \mathrm{d}$ ) is much lower than that of the more favourable Ecca facies and thus development requires far larger numbers of production boreholes. Although the exploration of aquifer occurrence and continuity is much more straightforward, therefore, the other hydrogeological problems discussed in relation to the Ecca aquifers of the Jwaneng wellfield, namely the evaluation of aquifer properties, unconfined storage coefficient and current recharge, present similar difficulties at the field investigation level and result in parallel problems when trying to make the critical decisions in groundwater supply engineering.

82. On the philosophical question of whether, in an arid region, groundwater resources should themselves be mined to promote mining activity, we consider the decision should be taken by the planners and politicians administering resources in the countries concerned; the responsibility of the engineers and scientists being to present clearly the extent to which such mining is likely to occur, and the probable state of resources when abstraction ceases, given the pump and well screen settings under consideration. In this instance, it was clear that there would be ample residual resources from which to supply the human and animal population of the area in the foreseeable future, albeit at increased cost. Arrangements are being made for the compensation of existing, and certain designated, users. 
83. The issue of overgrazing in the Kalahari is rather outside the scope of the Paper. There does not appear to be any reason why the groundwater supply requirements of the mining and livestock-rearing industries cannot be readily reconciled. However, we understand that there is a pressing need to extend the availability of boreholes for livestock watering into currently unexploited potential ranching areas and to reduce the livestock density in some areas where borehole water supplies are already developed.

84. We are grateful for Mr Spray's comments on the economic and planning considerations of groundwater supply and development, with which we concur. We were fortunate that the water demand estimates for the project were considered carefully from the outset, and, as far as compatible with available technology for high diamond recovery, efforts were made to minimize water consumption and maximize recirculation. Thus the estimated demand figure did not fluctuate greatly during the investigation and initial development phases of the project. This is not always the case, and unrealistic or widely varying demand estimates can, and often do, prejudice the logical progress of groundwater investigation and development.

85. The philosophical question raised on the pricing of water derived from a diminishing resource is an important and interesting one, which we believe should be considered more carefully in the economic evaluation of projects involving the mining of groundwater.

86. In reply to $\mathrm{Mr}$ Reeve, the groundwater quality was remarkably good for the arid zone, in almost all senses, over quite extensive areas. This strongly suggested that the resource must be largely comprised of groundwater recharge during an historic wetter period, when there were high rates of groundwater recharge with little evaporative concentration of chloride in the soil. The only exceptions were in the deeper part of the confined aquifer in the outlying area to the extreme west, where higher concentrations of numerous dissolved constituents were encountered. There was also some concern locally about fluoride concentrations but the combined wellfield supply is comfortably within World Health Organization recommended limits for potable supplies. Monitoring of groundwater quality, including sampling of individual pump discharge and depth sampling towards the bottom of selected boreholes, is being carried out on a regular basis, but during the first $1 \frac{1}{2}$ years' operational experience the quality picture has remained stable. One must retain apprehension that groundwater salinity will increase in some parts of the wellfield at some stage. If this occurs further engineering will be required to maintain a potable component of water supply for the mine from a given set of wellfield boreholes.

87. It has to be regretted, somewhat, that some $65-75 \%$ of the total supply of such good quality groundwater is being used consumptively as mine process water. There was no absolute need for this part of the supply to be of high quality, since there are only relatively marginal costs involved in upgrading the process plant to operate on saline water. However, given the time constraints associated with project development, it was not feasible to search simultaneously for a large saline groundwater resource and develop a dual supply system.

\section{Reference}

3. White R. J. Planning infrastructure for mining development in Botswana. Civil engineering problems overseas 1971. Institution of Civil Engineers, London, 1971, 11-25. 